\title{
Derechos absolutos, las minorías impopulares y el significado de la democracia
}

\section{Absolute rights, unpopular minorities, and the meaning of democracy}

Recibido: 10/03/2015 - Aprobado: 15/07/15

Natasa Mavronicola

Doctora en Derecho- Universidad de Cambridge Profesora Universidad Queen's de Belfast

(Irlanda del Norte)

n.mavronicola@qub.ac.uk

\section{RESUMEN}

La democracia y los derechos humanos constantemente son descritos como "las dos caras de la moneda» (Steiner, 2008). Esto se hace por lo general en referencia a los derechos políticos, como el derecho al voto, el derecho a la libertad de expresión, el derecho a la libertad de asociación y de reunión. Muchos comentarios han surgido al interior de la academia desde la década de 1990, haciendo énfasis en la naturaleza del «refuerzo mutuo» y la relación entre la democracia y los derechos humanos, además, de su compatibilidad con el concepto del derecho a la democracia.

Sin embargo, existen derechos que no están vinculados estrictamente al cumplimiento de procedimientos en la toma de decisiones democrática, especialmente aquellos derechos que afirman un estatus «absoluto». Este artículo aborda esta cuestión. Considera lo que implica un derecho absoluto y un enfoque sobre el derecho consagrado en el artículo 3 del Convenio Europeo de Derechos Humanos (CEDH), que establece que nadie será sometido a torturas, ni a penas o tratos inhumanos o degradantes, destacando dos grandes áreas en el que tal derecho puede funcionar para proteger a los marginados, las minorías impopulares o sin voz en contra de la voluntad mayoritaria o los argumentos del poder ejecutivo en procura del «interés general».

A continuación, se evalúa cómo la naturaleza y las implicaciones de un derecho absoluto, como el artículo 3 del CEDH puede verse relacionado con la democracia, y se examina la posibilidad de definir la democracia de una manera que abarque el respeto de tales derechos, para reconsiderar los límites de la democracia a la luz de los mismos. Se sugiere que la cuenta proporcionada indica la relación entre los derechos humanos y la democracia que debe dejar de ser vista a través de referencias a grandes rasgos a la interdependencia y el refuerzo mutuo. Esto implica que los abogados públicos deben afrontar la necesidad de abordar con precisión y de manera inequívoca lo que se quiere decir cuando se evoca la idea de la democracia, y en particular de la «democracia constitucional», sobre todo si se quiere tener una cuenta lúcida y honesta relación con los derechos fundamentales. En el contexto europeo, el Tribunal Europeo de Derechos Humanos está llamado a proporcionar dicha cuenta en su interpretación de los derechos humanos dentro de las «sociedades democráticas». 


\section{PALABRAS CLAVE}

Democracia, Derechos absolutos, minorías impopulares, Derechos Humanos.

\section{ABSTRACT}

Democracy and human rights are often portrayed as 'two sides of the same coin'. This is often done in reference to quintessentially political rights such as the right to vote, the right to freedom of expression, and the right to freedom of association and assembly. Much academic commentary since the 1990s emphasises the mutually reinforcing nature of the relationship between democracy and human rights and, further, supports the concept of a right to democracy.

Yet what of rights that are not strictly tied to the procedural fulfilment of democratic decision-making - particularly if such rights claim 'absolute' status? This paper addresses this issue. It considers what an absolute right entails and zooms in on the right enshrined in Article 3 of the European Convention on Human Rights (ECHR), which establishes that no one shall be subjected to torture or inhuman or degrading treatment or punishment, outlining two broad areas in which such a right can operate to protect marginalized, unpopular or voiceless minority groups against majoritarian will or executive 'public interest' arguments.

It then assesses how the nature and implications of an absolute right such as Article 3 ECHR can be seen to relate to democracy and examines the potential for defining democracy in a way that encompasses respect for such rights, or for reconsidering the limits of democracy in light of such rights. It is suggested that the account provided indicates that the relationship between human rights and democracy must cease to be viewed through broad-brush references to inter-dependence and mutual reinforcement. This entails that public lawyers must confront the need to address precisely and unequivocally what we mean when evoking the idea of democracy, and notably 'constitutional democracy',3 particularly if we wish to have a lucid and honest account of its relationship with fundamental rights. In the European context, the European Court of Human Rights is called upon to provide such an account in its interpretation of human rights within 'democratic societies'.

\section{KEY WORDS}

Democracy, absolute rights, unpopular minorities, Human Rights.

\section{INTRODUCCIÓN}

La democracia y los derechos humanos constantemente son descritos como «las dos caras de la moneda». Esto tiende a ser hecho en referencia a los derechos políticos por excelencia comprendidos en el derecho al voto, el derecho a la libertad de expresión, el derecho a la libertad de asociación y de reunión, entre otros, de hecho Steiner (2008) limita en gran medida su discusión a estos. Muchos comentarios académicos desde la década de 1990 consideran que la relación de refuerzo mutuo entre la democracia y los derechos humanos, es además compatible con el concepto de derecho a la democracia1. Para algunos, la tendencia de reconocer y discutir una tensión o incluso un conflicto entre la democracia y los derechos humanos, se encuentra fuera de contexto y es vista como una simple cuenta

\footnotetext{
1 Además, el párrafo 8 de la Declaración de Viena de 1993, establece: «La democracia, el desarrollo y el respeto de los derechos humanos y las libertades fundamentales son interdependientes y se refuerzan mutuamente. La democracia se basa en la voluntad libremente expresada de los pueblos de determinar sus propios sistemas políticos, económicos, sociales y culturales y su plena participación en todos los aspectos de sus vidas». (Asamblea General de la ONU, Declaración y Programa de Acción de Viena de 12 de julio de 1993).
} 
de los dos conceptos importantes, particularmente a la luz del concepto inclusivo de la «democracia constitucional».

Sin embargo, los derechos que no están vinculados estrictamente al cumplimiento de procedimientos de toma de decisiones democráticas -especialmente aquellos derechos que afirman un estatus «absoluto», como es el caso del artículo 3 del Convenio Europeo de Derechos Humanos («CEDH»)-, dispone que nadie será sometido a torturas ni a penas o tratos inhumanos o degradantes; asunto que será objeto de estudio en el presente artículo. Se considera que implica un derecho absoluto y se da entonces una recapitulación de sus implicaciones jurídicas concretas y centradas en el derecho consagrado en el artículo 3 del CEDH. Después se considerará brevemente dos grandes áreas en las que opera el derecho de proteger a los grupos minoritarios, marginados o impopulares contra la voluntad mayoritaria o los argumentos del ejecutivo a favor del interés público, entonces se evalúa la forma en que la naturaleza y las implicaciones de este derecho absoluto puede verse relacionado con la democracia y lo que esto implica en la relación entre la democracia y los derechos humanos.

El análisis se centra en tres elementos:

i). El grado en que el artículo 3 del CEDH opera para el 'triunfo' de la voluntad de las mayorías y/ 0 de las instituciones mayoritarias o políticamente responsables "democráticas», y/o las concepciones de este último, el interés público;

ii). La protección conferida por el artículo 3 del CEDH sobre las minorías impopulares que a menudo no tienen voz en el proceso democrático; y

iii). La posibilidad de definir la democracia de una manera que abarque el respeto de un derecho como el artículo 3, para reconsiderar los límites de la democracia a la luz de tal derecho(s).

La interacción que se describe en este artículo, indica que la relación entre los derechos humanos y la democracia no debe verse a través de una mirada color rosa, 0 a través de referencias a grandes rasgos de la interdependencia y el refuerzo mutuo. La definición y la delimitación del derecho absoluto consagrado en el artículo 3, entre otros derechos, pueden tener un impacto directo en la definición o delimitación de la democracia. Esto implica una necesidad de enfrentar con precisión y de manera inequívoca lo que se abarca en la evocación de la idea de la democracia, sobre todo si se busca tener una lúcida y honesta relación con los derechos humanos. Dada la importancia de la naturaleza y las implicaciones del artículo 3 del CEDH, el Tribunal Europeo de Derechos Humanos («TEDH») debe enfrentarse a la necesidad de proporcionar una definición oficial de su concepción de la democracia, a la luz de la interacción que se describe en este artículo, ya que así es como la interacción es más amplia entre las alusiones a la democracia y los derechos consagrados en el CEDH.

\section{DEMOCRACIA: UNA BREVE RESEÑA}

La democracia es una palabra que se usa en discusiones cotidianas, trabajos académicos, debates políticos, entre otros variados escenarios. Un elemento clave de la utilización de la palabra «democracia», sobre todo en relación con los derechos humanos, es sin duda la diferencia de matices o a veces la rigurosidad en el contenido que se le atribuye por cada articulación y articulador de la misma, además de una clara falta de franquesa y definición exhaustiva de este contenido en tales articulaciones. Para los efectos de este artículo, el autor se refiere a un espectro de significados atribuidos a menudo a la palabra "democracia» y tentativamente a evaluar lo que es su concepción predominante.

Los orígenes de la democracia por lo general se dice que se encuentran en el $\delta \eta \mu о \kappa \rho \alpha \tau i \alpha$ ateniense (demokratía), que se traduce como «gobierno del pueblo» y que abarcó la toma de decisiones por la mayoría en las reuniones de los ciudadanos considerados habilitados para votar (Marks \& Clapham 2005). Hoy en día, esto se ha traducido en abarcar la voluntad del pueblo, expresado a través de elecciones libres y periódicas sobre la base del sufragio universal, transmitiendo 
la autoridad del gobierno, por lo general sobre una base representativa, tal como se indica en el artículo 21 (3) de la Declaración Universal de los Derechos Humanos $^{2}$. Esto, por supuesto, plantea cuestiones de definición significativas (Effeh, 2007). Los modelos deliberativos y participativos constituyen también modelos de procedimiento con alternativas pertinentes. No obstante, los parámetros generales de esta concepción procedimental de la democracia se transportan en estos requisitos, así como el punto adicional y fundamental relativo a los «ganadores» de dicho proceso: el aspecto clave del gobierno de la mayoría. La voluntad de la mayoría o «el mayor número» sustenta las decisiones cruciales, ya sean las de los representantes que elijan o las de las legislaturas, por poner dos ejemplos que se encuentran en el corazón de esta concepción de la democracia. Sadurski (2006) se refiere al 'gobierno de la mayoría' basado en el diseño institucional (que es, sujeto a todas las salvedades y reservas posibles, en el núcleo duro e irreductible de toda democracia). En un nivel más general, Effeh (2007) señala que no puede haber ninguna definición válida de la democracia que excluya la voluntad o la autoridad del pueblo y sugiere que «la democracia siempre se debe definir en relación con estos factores fundamentales» (p. 93).

En una parte notable sobre los derechos de los marginados bajo la CEDH, Harvey y Livingstone (2001) señalan que «si el TEDH tiene que ver con el fortalecimiento de la democracia y los derechos humanos de protección, entonces se debe tomar una posición clara con referencia a los grupos silenciados dentro del proceso democrático» (pp. $444,445)$. Parte de este punto destaca los problemas planteados en la particularización o concreción del proceso democrático y, en particular, el problema de la exclusión. El proceso, tal como se define en un Estado determinado, puede excluir a ciertos individuos, ya sea directamente, por ejemplo a través de la privación de derechos explícitos, 0 indirectamente, por ejemplo a través de definiciones particulares de la ciudadanía. Tal comentario plantea sin duda la posibilidad de una concepción del proceso democrático, que se adapte a la necesidad de actuar en beneficio y representación verdaderamente de todos, así como tal vez la necesidad de considerar el por qué están excluidos del proceso democrático como se indicó anteriormente. Esto incluiría los grupos que van desde los niños hasta los presos solicitantes de asilo.

Este punto nos anima a tener una perspectiva más amplia de las cuentas de procedimiento, y puede estar vinculado a la tesis de Lincoln (1863): «un gobierno del pueblo, por el pueblo y para el pueblo», teoría que va más allá de la pregunta del ¿quién la incorpora y para quién? El énfasis en la consecución del interés público de manera eficaz y sostenible acogido por y para el pueblo, aun cuando no se puede correlacionar con los aparentes deseos contemporáneos del electorado, subyace entonces la distinción hecha por algunos entre democracia y populismo (Pinelli, 2011).

¿Hay más? Hailsham (1976) se refirió al sistema de la soberanía parlamentaria del Reino Unido como «una dictadura electiva». Esto fue en parte una referencia al predominio del poder ejecutivo sobre el legislativo en el Reino Unido, pero también en parte una alusión a la necesidad de mayores controles y equilibrios para salvaguardar algo más profundo que podría ser llevado por un sin control, incluso por el Parlamento omnipotente, cuando este último -al menos, la Cámara de los Comunes- es una institución «democrática». Este último aspecto es quizás lo que sustenta en gran medida las concepciones actuales de la «democracia constitucional» (Jowell, 2006), que abarca no sólo un aspecto de procedimiento democrático -como se describe anteriormente- sino también un aspecto sustantivo que comprende ciertos derechos y libertades fundamentales. Esto incluye en particular los derechos que

\footnotetext{
2 El artículo 21 (3) de la Declaración Universal de Derechos Humanos dice: «La voluntad del pueblo es la base de la autoridad del poder público; esta voluntad se expresará mediante elecciones auténticas y periódicas realizadas por sufragio universal e igual y por voto secreto u otro procedimiento equivalente a libertad del voto».
} 
protegen el proceso democrático, como la libertad de expresión, la libertad de asociación, la libertad de reunión, etc. Muchos comentarios sobre la democracia sugieren que la «democracia», ni en la teoría ni en la práctica, es una regla del gobierno de la mayoría ${ }^{3}$. Además, Dworkin (1996) parte del punto de que la democracia es imperfecta y sin libertades individuales, lo que sugiere que la democracia requiere una verdadera comunidad política basada en las condiciones morales, incluyendo el mismo respeto y preocupación por todos los participantes.

Teniendo en cuenta la relación entre la democracia y el CEDH, Letsas (2004) señala que no es necesario ser sorprendidos por cualquier supuesto conflicto entre la democracia y el CEDH. Primero, fue la democracia la que permitió la institucionalización de los derechos humanos. El CEDH ha sido firmado y ratificado por los miembros del Consejo de Europa, de conformidad con sus procedimientos democráticos internos. En segundo lugar, es el valor de la democracia una vez más que, en la cuenta interpretativa, conlleva a examinar la legislación pasada, tanto nacional como internacional, a fin de determinar los correctos principios de interpretación. Si no hubiera habido decisiones políticas del pasado que reconozcan la dimensión moral de los derechos protegidos, seríamos incapaces de hacer justicia en una dimensión interpretativa jurídicamente vinculante. En tercer lugar, independientemente de la historia, sería muy difícil aceptar que alguna vez pudo haber democracia sin gente disfrutando de una esfera de la libertad personal.

En tal comentario se encuentra presente la escuela de pensamiento del 'refuerzo mutuo'. Al respecto, Steiner (2004) señala:

La democracia es una empresa colectiva, una forma de organizar el poder político dentro de una comunidad a fin de lograr la autodeterminación colectiva. Junto con los derechos humanos, su estructura, instituciones y procesos constituyen el marco fundamental en el que la elección individual se ejerce en la vida política. Y concluye: Cada una, sin la compañía de la otra, puede darse cuenta de sólo una parte de su potencial y sobrevive por su cuenta y riesgo. Juntas, se complementan y fortalecen entre sí. Hoy en día los derechos humanos y la democracia forma parte de la misma gran narrativa de la aspiración y esperanza para nuestro mundo (pp. 279-303).

Estos comentarios indican que la democracia y los derechos humanos se refuerzan mutuamente en la expresión de la voluntad individual y colectiva. Ellos se centran sobre la instrumentalidad de cada una (los derechos humanos y la democracia) a apoyar a la otra, por ejemplo, el valor del derecho humano a la libertad de expresión en la defensa de la democracia. Habermas (1996:127) también parece sugerir que la democracia procedimental, en la forma de deliberación en la que se interpreta, establece la naturaleza del refuerzo mutuo de los derechos fundamentales y la soberanía popular (según sus propias palabras «la co-originalidad de la autonomía cívica y privada»), proponiendo que la soberanía popular opera para salvaguardar los derechos individuales, mientras que esos derechos son pre-requisitos para el ejercicio de la soberanía popular, con el argumento de que «la soberanía popular y los derechos humanos van de la mano». Cohen (1988) sostiene además que los valores políticos liberales igualitarios y encarnados, entre otras cosas, en lo que él denomina «la libertad religiosa, expresiva y moral» debe ser vista como interna a la democracia y no como limitaciones de la misma.

¿Pero esto comprende la «historia completa» con respecto a la relación entre la democracia y los derechos humanos? El siguiente análisis sugiere que

3 ¿Qué es exactamente la democracia? No debemos identificar la democracia con el gobierno de la mayoría. La democracia tiene demandas complejas, que sin duda incluyen la votación y el respeto de los resultados electorales, pero también requiere la protección de las libertades, el respeto de los derechos legales, la garantía de la libre discusión y la distribución sin censura de noticias y comentario justos. Incluso las elecciones pueden ser profundamente defectuosas si se producen sin que los diferentes lados consigan una oportunidad adecuada para presentar sus respectivos casos, o sin el electorado disfrutando de la libertad para obtener noticias y tener en cuenta los puntos de vista de los protagonistas de la competencia. La democracia es un sistema exigente, y no sólo una condición mecánica (como regla de la mayoría) tomadas de forma aislada. (Amartya, 1999 pp. 3-9-10). 
no lo hace. Si el conflicto es interno a la «democracia constitucional», con sus pilares de procedimiento y de fondo, o externo, entre la democracia, tan ampliamente concebida, y los derechos humanos (algunos), se requiere entonces el reconocimiento y la confrontación transparente, sobre todo por el TEDH (Lyell, 1997).

Parecería que no solo en la mayoría de ocasiones en las que se utiliza de paso el término «democracia», sino también en las cuentas abiertas de la relación entre la democracia y los derechos humanos, la articulación completa de los contornos del significado de la democracia se suprime. Sin embargo, la mayoría de veces, estas alusiones, particularmente cuando son evocadas de paso y sin un intento de definición, dan la impresión que son abarcadas como un elemento necesario pero tal vez no lo suficiente, como una especie de representación del modelo de la regla de participación o de cumplimiento de los intereses de la mayoría. Esto es claro, por ejemplo en Letsas (2004) en su discusión de la interrelación entre la democracia y los derechos consagrados en el CEDH y en el discurso de Steiner (2008).

A la luz de esta observación, se pasa a considerar la interacción entre el derecho absoluto consagrado en el artículo 3 del CEDH y la democracia, al ver que la naturaleza absoluta del artículo 3 implica tanto en abstracto como en concreto la protección de los grupos de minoría impopular y los marginados. Luego se evalúan las posibles implicaciones de estas en la delimitación del concepto de democracia, ofreciendo alternativas para la interpretación de la relación entre el artículo $3 \mathrm{CEDH}$ y las concepciones de la democracia. Esta evaluación muestra que las alusiones a la relación de refuerzo mutuo entre la democracia y los derechos humanos son insuficientes, en términos de abordar los conflictos discutibles que proporcionan claridad en la interpretación de la CEDH, y sugieren que el TEDH se ve obligado a proporcionar una cuenta autorizada de cómo se concibe en términos generales la idea de la democracia y su relación con los derechos consagrados en el $\mathrm{CEDH}$.

\section{EL CARÁCTER ABSOLUTO DEL ARTÍCULO 3 DEL CEDH}

El artículo 3 de la CEDH ha sido descrito como un derecho absoluto, como lo afirma el Tribunal Europeo de Derechos Humanos ("TEDH "o" la Corte "o" el Tribunal de Estrasburgo») y muchos comentaristas. Es importante en este momento señalar que «el Tribunal Europeo de los Derechos Humanos, y la propia Convención, forman una parte importante de la constitucionalización europea e internacional» (Fiona de Londras, 2013), y a su vez en la función constitucionalista ampliamente reconocida del TEDH contra los Estados Contratantes del CEDH; finalmente se observa que la jurisprudencia del TEDH sobre el artículo 3, en particular, a la luz de su carácter absoluto, ha sido descrita como poseedora de una calidad "constitucional» (Dzehtsiarou y Greene, 2011). En su jurisprudencia, el Tribunal de Estrasburgo centra su discurso respecto a lo que implica el carácter absoluto del artículo 3 en una yuxtaposición, contrastando el artículo 3 de los derechos que permitan la «cualificación»: en la forma de excepciones legales, o interferencias (en lugar de violaciones ilegales de los derechos) (Mavronicola, 2012).

\section{EI TEDH reitera con frecuencia:}

La Convención prohíbe en términos absolutos la tortura y los tratos inhumanos o degradantes, independientemente de la conducta de la víctima. A diferencia de la mayoría de las cláusulas sustantivas de la Convención y de los Protocolos 1 y 4, del artículo 3 no prevé excepciones y, en virtud del artículo 15 (2), no puede haber ninguna excepción a la misma, incluso en el caso de una emergencia pública que amenaza la vida de la Nación. (Irlanda v Reino Unido, 1979-1980. 2 EHRR 25)

Esto refleja la idea de que un derecho absoluto es aquel del que no se puede justificar su trasgresión y debe ser cumplido sin excepción, proposición presentada por Gewirth (1981). En respuesta a los argumentos relativos de la abrumadora necesidad de los Estados de protegerse y proteger a sus ciudadanos de la amenaza del terrorismo, argumenta que se relacionan con el interés público $(y, a$ 
menudo, con la voluntad pública) un aspecto de la democracia. EI TEDH ha añadido:

El artículo 3 consagra uno de los valores fundamentales de la sociedad democrática. El Tribunal es consciente de las inmensas dificultades que enfrentan los Estados en los tiempos modernos en la protección de sus comunidades contra la violencia terrorista. Sin embargo, incluso en estas circunstancias, la Convención prohíbe en términos absolutos la tortura o los tratos inhumanos o degradantes, independientemente de la conducta de la víctima. (Chahal v Reino Unido, 1997).

La gran Sala del TEDH ha abordado el sometimiento de un secuestrador a las amenazas de tortura con el fin de revelar el paradero y potencialmente salvar la vida del niño secuestrado (en la que el secuestrador confesó el asesinato del niño). En el momento en que las amenazas tuvieron lugar, la situación posiblemente podría ser vista como algo parecido a una vida real marcando un escenario crucial (Bjorge, 2011). La gran Sala, sin embargo, afirmó:

El Tribunal de Justicia ha confirmado que, incluso en las circunstancias más difíciles, tales como la lucha contra el terrorismo y el crimen organizado, la Convención prohíbe en términos absolutos la tortura y los tratos inhumanos o degradantes, independientemente de la conducta de la persona en cuestión. La naturaleza de la infracción supuestamente cometida por la demandante no es pertinente a los efectos del art.3 (Gäfgen v Alemania (2011).

De este modo, se puede decir que en el carácter absoluto del artículo 3 se encuentran tres elementos clave: i). No contiene excepciones construidas. Esto se puede contrastar con los derechos de los calificados en virtud del CEDH, como los artículos 8, 9, 10, 11 , que prevén la injerencia justificada en la medida necesaria en una sociedad democrática en la búsqueda de un objetivo legítimo4; ii). No obstante lo dispuesto es permisible. El artículo 15 (2), prevé la derogación en caso de guerra o de otro peligro público que amenace la vida de la nación, y no permite la derogación del artículo $3^{5}$; iii). La conducta de la víctima es irrelevante en lo que respecta a su protección en virtud del artículo 3 (Chahal vs. Reino Unido).

Esto implica que el derecho consagrado en el artículo 3 no puede ser desplazado. En ese sentido, es el último 'triunfo', a partir del análisis de Dworkin (1977). La voluntad de (lo que ampliamente se percibe como lo que podría pasar) los organismos democráticos tales como las elegidas legislaturas, no pueden desplazar el artículo 3. Los argumentos relativos al interés público, incluyendo la necesidad de la acción del Estado de proteger la vida, no pueden tampoco desplazar este artículo. El artículo 3, por lo tanto, abarca una esfera de la obligación legal que prevalece sobre la voluntad de la mayoría y (lo que algunos, especialmente los elegidos políticamente o los individuos responsables, podría afirmar que es) el interés de la mayoría, son dos elementos que a menudo se ven, y que reposan en el corazón de las nociones de democracia, en particular «por el pueblo y para el pueblo» ideales, como se mencionó anteriormente.

\section{PROTECCIÓN DE LAS PERSONAS PERTENECIENTES A GRUPOS MINORITARIOS MARGINADOS CONFORME CON EL ARTÍCULO 3}

Como se indicó en la discusión anterior sobre la naturaleza absoluta del artículo 3 , el derecho consagrado en él será el triunfo que refleja la voluntad pública (si comunica imperfectamente), tal como se expresan a través de las instituciones representativas, como la Casa de los Comunes del Parlamento del

4 Véase, por ejemplo, el artículo 10 (2) del CEDH: «El ejercicio de estas libertades, que entrañan deberes y responsabilidades, podrá ser sometido a ciertas formalidades, condiciones, restricciones o sanciones, previstas por la ley y son necesarias en una sociedad democrática, en interés de la seguridad nacional, la integridad territorial o la seguridad pública, la prevención de desórdenes o delitos, para la protección de la salud o de la moral, la protección de la reputación o de los derechos ajenos, para impedir la divulgación de informaciones confidenciales o para garantizar la autoridad y la imparcialidad del poder judicial».

5 Véase el artículo 15 (2) del CEDH: «No obstante lo dispuesto en el artículo 2, salvo para el caso de muertes resultantes de actos lícitos de guerra, ni de los artículos 3, 4 (párrafo 1) y 7 se efectuará conforme a esta disposición». 
Reino Unido, o los actos emitidos por el ejecutivo que pretenden velar por el interés público (por la gente y para la gente). En efecto, el artículo 3 se ha hecho con claridad para que en un número de ocasiones, en particular se proteja a las personas pertenecientes a minorías impopulares, marginadas, o políticamente impotentes.

Los ejemplos abundan. Dos grupos minoritarios claves que se pueden tomar como puntos focales para fines ilustrativos, son los prisioneros y los solicitantes de asilo. Ambos grupos tienen características que son importantes para los fines de esta discusión. En primer lugar, al menos en el Reino Unido, que no tienen derecho al voto y por lo tanto no son participantes directos en los procesos democráticos, mientras que mantienen su condición de presos o solicitantes de asilo, como se describe anteriormente ${ }^{6}$. Muchos otros países en el Consejo de Europa, restringen su participación política de manera significativa ${ }^{7}$. En segundo lugar, no son altos en popularidad entre aquellos que tienen voz en el proceso democrático.

La jurisprudencia relativa a la protección de los prisioneros en virtud del artículo 3 es extensa y sólida. La Gran Sala ha afirmado que un individuo profundamente impopular que fue encarcelado por haber secuestrado y asesinado a un niño, pero que había sido amenazado con la tortura en violación del artículo 3 tenía derecho a una indemnización (Gäfgen vs Alemania, 2011). Otros casos han establecido extensos requisitos previstos en el artículo 3 en relación con el trato de los reclusos y las condiciones de detención. Un ejemplo entre muchos relativo a las condiciones de la prisión y el artículo 3 , los Pares $v$ Grecia establecieron que el confinamiento en una celda sin ventilación y sin ventana en verano y cuando el solicitante tenía que usar el baño, en presencia de otro interno y viceversa constituían un trato inhumano. El sometimiento a condiciones similares a los detenidos y solicitantes de asilo se han encontrado recientemente por estar en violación del artículo 3 en MSS vs. Bélgica y Grecia, la situación financiera desesperada de Grecia no proporciona ninguna excusa. Por otra parte, se requieren medidas especiales para proteger a un interno de la prisión en la que o él o ella enfrente un riesgo de suicidio (Keenan vs. Reino Unido (2001).

El Tribunal también ha impuesto derechos estrictos en virtud del artículo 3 a las autoridades Estatales para proporcionar atención médica adecuada a los presos. En un caso reciente, el Tribunal de Estrasburgo estipuló que la atención médica proporcionada «debe adaptarse a las demandas legítimas de prisión, pero siguen siendo compatibles con la dignidad humana y el debido cumplimiento de las obligaciones positivas por parte del Estado», lo que sugiere que esto le corresponde garantizarlo a las autoridades nacionales, en particular, el diagnóstico y la atención han sido rápidos y precisos, y la supervisión por personal médico ha sido regular y sistemática y participan en una estrategia terapéutica integral (Jashi vs. Georgia, 2013). Estos derechos son sin costo, y van más allá de las obligaciones que el Estado adeuda a los individuos dentro de su jurisdicción que no están en la cárcel. Ellos son significativos en la protección de un grupo vulnerable que está sujeto al control del Estado.

La jurisprudencia de la Corte es tan robusta en la protección de los solicitantes de asilo. Casos como Chahal vs. Reino Unido, Saadi vs. Italia, MSS vs. Bélgica y Grecia y Hirsi Jamaa vs. Italia, que han consolidado fuertes obligaciones con respecto a la prohibición de la expulsión de las personas a los Estados donde se enfrentan a un riesgo real de tortura u otros en el artículo 3 proscritos a malos tratos, independientemente del apoyo público significativo para su expulsión o los argumentos de los gobiernos estatales CEDH (en particular el Reino Unido)

6 Harvey y Livingstone (2001). Señalan que son más silenciados, al menos en lo que respecta el discurso político oficial, que los presos.

7 El tema ha sido objeto de la jurisprudencia sustancial del TEDH, que ha dejado claro que las prohibiciones generales son contrarios al derecho al voto consagrado en el artículo 3 del Protocolo 1 del CEDH. 
en cuanto a sus intereses de seguridad nacional ${ }^{8}$. Se ha observado que se han expandido significativamente en la protección conferida a este grupo de individuos por derecho de los refugiados. Las condiciones de detención inhumanas o degradantes de los solicitantes de asilo también han sido atacadas por la Corte, como se indicó anteriormente, en MSS vs. Bélgica y Grecia, que se enfrenta a las presiones ejercidas por la situación financiera en Grecia.

Por lo tanto, si bien, a primera vista las minorías no tienen un lugar especial dentro de la Convención (Marquand, 1994), el alcance de la protección conferida a estos grupos por el artículo 3 del CEDH es sustancial y se mantiene firme en contra de su posición marginada y posiblemente impopular en la mayoría de estados del CEDH. La naturaleza absoluta del artículo $3 \mathrm{CEDH}$ opera de lleno al triunfo de la voluntad política en el ámbito de aplicación del artículo 3. En este sentido, el impacto significativo del artículo 3 en la protección de estas personas, nos permite reconsiderar la interacción, la delimitación de las nociones de democracia y los derechos humanos.

\section{EI DERECHO ABSOLUTO CONSAGRADO EN EL ARTÍCULO 3 Y LA DEMOCRACIA: CONCEPTUALIZANDO LA INTERACCIÓN}

La democracia hace su aparición en varias ocasiones en el texto de la CEDH. Como lo señala O'Connell (2006): «El concepto de una sociedad democrática es un hilo conductor a lo largo de la Convención». La Convención identifica «una democracia política efectiva» como una de las garantías fundamentales de los derechos humanos y las libertades fundamentales (Preámbulo). Cuando se trate de limitar algún derecho, solo será posible en la medida en que sea «necesaria en una sociedad democrática» (Arts. 8, 9, 10 y 11). La Corte ha sido llamada a considerar lo que es necesario en una sociedad democrática, en gran parte de su jurisprudencia en materia de derechos absolutos, no ha sido menos importante el derecho a la libertad de religión. Sin embargo, la redacción es el gran ausente en el artículo 3 del CEDH, debido a su naturaleza absoluta, como se examinó anteriormente.

Si no hay espacio para infringir el artículo 3 en la medida necesaria en una sociedad democrática, ¿cuál es la relación entre la democracia y el artículo 3 del CEDH? Sorprendentemente, en su discurso sobre el carácter absoluto del artículo 3 del Convenio Europeo, el Tribunal de Estrasburgo a menudo describe que el artículo 3 se consagra como uno de los valores fundamentales de la sociedad democrática. No siempre está claro qué la concepción de la sociedad democrática en el TEDH es contemplada al hacer esta declaración. Ciertamente, una sociedad en la que los opositores políticos del gobierno de turno se enfrentan a un riesgo de tortura $u$ otros malos tratos, como una quintaesencia dictatorial. Sin embargo, el artículo 3 no protege de manera exhaustiva las libertades políticas -el derecho a no ser sometido a torturas ni a tratos o penas crueles- y capta un esquema mucho más amplio de la situación del preso político torturado, y degradado.

En efecto, el artículo 3 posee dos características importantes, que hacen que su interacción con las concepciones de la democracia particularmente sea interesante. El primero es su carácter absoluto, que no permite la interferencia en la medida necesaria en una sociedad democrática; la segunda es que el artículo 3 no está conectado de forma indeleble en la realización de los procedimientos democráticos eficaces. Este último punto tiene que ver con el hecho de que el artículo 3 no es francamente un derecho político ligado al proceso democrático como es el derecho al voto, la libertad de expresión y la libertad de asociación, por dar tres

8 Véase, por ejemplo, Chahal vs. Reino Unido: «La Corte es consciente de las inmensas dificultades que enfrentan los Estados en los tiempos modernos en la protección de sus comunidades contra la violencia terrorista. Sin embargo, incluso en estas circunstancias, la Convención prohíbe en términos absolutos la tortura o los tratos o penas inhumanos o degradantes, independientemente de la conducta de la víctima». 
ejemplos ${ }^{9}$. A la luz de estos dos elementos, se procede a considerar tres aspectos potenciales de pensamiento en la interacción entre el derecho absoluto consagrado en el artículo 3 del CEDH y la democracia ${ }^{10}$.

El primer enfoque potencial es adoptar una construcción de la noción de «democracia» que admita no sólo los derechos que son fundamentales para el proceso democrático, sino también que los derechos pueden triunfar de los resultados de dicho proceso democrático, pero que protejan ciertos parámetros fundamentales de la dignidad del ser humano. Tal enfoque reflejaría la afirmación del Tribunal de Derechos Humanos que el artículo 3 consagra como uno de los valores fundamentales de la sociedad democrática. Se trata de un enfoque que asigna un significado particularmente intrínseco a la noción de "democracia», delimitando su limbo procesal de tal manera que se otorgue, en su extremidad sustantiva, una esfera de la dominación de ciertos derechos vistos como fundamentales para la democracia, aunque no claramente instrumental 0 subyacente de alguna manera el proceso democrático. Al respecto Harvey (2004) señala:

Cuando vivimos en una democracia constitucional, entendemos que esto significa que la mayoría no siempre va a salirse con la suya. Hay algunas cosas que incluso un gobierno elegido democráticamente, no debe permitir. La argumentación continuará en la interpretación y aplicación de las «condiciones democráticas», pero sospecho que creemos intuitivamente que la idea de estas condiciones es aceptable. (p. 500, 510).

Este es un enfoque que no siempre se expresa claramente por las escuelas de pensamiento de «refuerzos», que, en su cuenta de la interacción entre los dos, tiende a centrarse en el papel fundamental de la democracia y los derechos humanos en la promoción de unos a otros. Esto parece dar lugar a algunas dificultades para establecer cuándo y cómo la democracia implica no sólo el derecho a no ser sometido a tortura o tratos inhumanos o degradantes, sino también que este derecho es el triunfo de la voluntad o el interés de la mayoría, que, como se ha analizado anteriormente, es visto por muchos como la mentira en el núcleo de la democracia. Por lo tanto, el discurso sobre la noción de la «democracia constitucional» se ha referido a los «continuos ajustes» de los «principios potencialmente conflictivos e instituciones 'encapsuladas' en los procesos y las instituciones democráticas en las concepciones, y los derechos basados en el estado de derecho», que están abiertos a diversas interpretaciones y, por lo tanto, al conflicto (Pienelli, 2011).

Por desgracia, los derechos de internalización como el artículo 3 de la democracia o la «democracia constitucional», como muchas etiquetas no resuelven la "paradoja democrática», ni señalan cómo se produce la delimitación y el por qué el derecho absoluto consagrado en el artículo 3 funciona como lo hace dentro de esta concepción amplia de la democracia. Si sólo es posible racionalizar los derechos superando los procesos democráticos al referirse de nuevo al fundamento procesal de permitir a los individuos o grupos tener voz, la entrada en la toma de decisiones y la forma en la salvaguardia de los derechos absolutos, incluso contra la voluntad mayoritaria, no sólo se tendrían problemas para adaptar el artículo 3 dentro de esta lógica, sino también para recurrir al instrumentalismo y llegar a la paradoja fundamental: la democracia derrotada por la democracia que es sostenida (Rummens, 2007). Sin embargo, esto no nos dice nada acerca de cómo los componentes internos de la democracia supuestamente deben ser delimitados.

Este es un enfoque que percibe la democracia y los derechos humanos como potencialmente involucrados en un conflicto abierto, y este conflicto podría

9 Tales derechos se consideran fundamentales para los modelos procesales de la democracia representativa y que incluyen la democracia deliberativa.

$10 \mathrm{El}$ análisis que sigue no aborda los temas «verticales» en relación con la legitimidad democrática de los tribunales internacionales o regionales. 
decirse que es especialmente marcado cuando los derechos humanos operan para proteger a los grupos minoritarios que se encuentran fuera del proceso democrático. Es un enfoque que quizá refleja muchas referencias a la democracia en el derecho público y la literatura de los derechos humanos en los que la naturaleza «no democrática» de los derechos humanos o los derechos humanos de adjudicación, la «dificultad contra-mayoritaria» (Bickel, 1962), o el peligro de la supremacía judicial, fue señalada por los comentaristas.

Este enfoque, sin embargo, no iba a abrazar necesariamente las opiniones que condenan el predominio de los derechos sobre la 'voluntad democrática'. Esto sin duda sugiere que tomar la posición de que la democracia no puede hacer mal y que es lo último bueno -sería una posición particularmente común en los comentarios en apoyo del principio de la soberanía parlamentaria del Reino Unido-, y no es sostenible desde un punto de vista jurídico o normativo, por lo menos (a los efectos de este artículo) bajo la rúbrica de la CEDH.

De hecho, la opinión de Christiano (2008), a este efecto es evidente en su definición de la democracia:

El término «democracia» (...) se refiere de manera muy general a un método de decisión de grupo, haciendo que se caracterice por un tipo de igualdad entre los participantes en una etapa esencial de la toma de decisiones colectivas. Deberán tenerse en cuenta cuatro aspectos de esta definición. En primer lugar, las preocupaciones democráticas de toma de decisiones colectivas, y me refiero a las decisiones que se hacen para grupos y que son vinculantes para todos los miembros del grupo. En segundo lugar, esta definición significa cubrir una gran cantidad de diferentes tipos de grupos que pueden llamarse democráticos. Así que no puede haber democracia en las familias, las organizaciones de voluntarios, empresas económicas, así como los estados y las organizaciones transnacionales y globales. En tercer lugar, la definición no tiene la intención de llevar a cualquier peso normativo a la misma. Es muy compatible con esta definición de democracia que no es deseable tener la democracia en un contexto particular. Así que la definición de la democracia no resuelve alguna pregunta normativa. En cuarto lugar, la igualdad requerida por la definición de democracia puede ser más o menos profunda (...).

Así, este enfoque reconoce la necesidad de buscar respuestas a cuestiones normativas relativas a los derechos, en particular los derechos absolutos, como el artículo 3, fuera de la protección de la democracia. La solución del conflicto en el plano normativo sigue siendo, por supuesto, un ejercicio muy difícil, pero el enfoque del reconocimiento del conflicto podría decirse que permite que se produzca de una manera más transparente. Por otra parte, en el nivel concreto de considerar cómo el artículo 3 del CEDH -es un derecho ya consagrado y ejecutado- en un régimen regional robusto en los de derechos humanos regionales, que opera en relación con las fuerzas o los objetivos democráticos, y puede servir para aclarar que la protección de la democracia no explica su naturaleza absoluta.

Tal vez se necesita algo más. Se podría argumentar que el conflicto, ya sea en una primera aproximación, ya sea interno o uno externo (segundo método), requiere la resolución a través de un meta-principio. De acuerdo con un tercero, o seguido enfoque, la igualdad puede servir a propósito de abordar el conflicto. El argumento sería que, particularmente en relación con los grupos minoritarios impopulares, marginados o silenciados, la operación de los derechos absolutos sirve para salvaguardar un núcleo mínimo de dignidad humana que es fundamental para la igualdad de todos los seres humanos. Por lo tanto un derecho como el artículo $3 \mathrm{CEDH}$ podría ser retratado tanto como intrínsecos e instrumental hacia la democracia. Este es un argumento que parece subyacer a la posición de Ronald Dworkin, que presenta la democracia y que exige «que las decisiones colectivas deben ser realizadas por instituciones políticas cuya estructura, composición y prácticas consisten en tratar a todos los miembros de la comunidad, como individuos, con igual consideración y respeto» (Dworkin, 1996).

Sin embargo, surgen dos problemas en el intento de presentar este análisis como la solución del 
problema. Uno de ellos es el argumento de que, cuando se trata con el artículo 3, esto se extiende a la igualdad no muy lejana. En términos del artículo 3 pueden defender el ideal que todas las personas deben ser tratadas como fines y no como medios para un fin, y en esta medida se basa en el ideal de la igualdad. Sin embargo, la condensación del artículo 3 de las condiciones, a la igualdad no capta el discurso rico y polémico a la interpretación y aplicación de su términos (Mavronicola, 2012). Otro, problema fundamental, es el siguiente: incluso si se acepta que un derecho absoluto, como el artículo 3 que defiende la igualdad, como un ideal indeleble ligado a la democracia, la pregunta entonces sería con qué precisión se manejó. Si está tan ligada debido al respeto por la igualdad es la condición sine qua non para la consecución de la democracia procedimental, entonces no es un meta-principio en absoluto, y conlleva a la paradoja instrumentalista de nuevo: de que la democracia derrotó a la democracia que es confirmada.

Si por el contrario, consideramos que la igualdad esta indeleblemente ligada a la democracia porque creemos que la democracia está allí para asegurar la igualdad (como indica Dworkin), entonces la igualdad parece ser el ideal supremo, y las diferentes concepciones de la democracia son simplemente para ser evaluadas en relación con ella, lo que implica la posibilidad de conflictos, superando los derechos (libremente) derivados de la igualdad. Esto nos lleva al segundo enfoque, pero con la igualdad como valor rector. La subsunción de la democracia y los derechos humanos en virtud de la igualdad puede servir para explicar la naturaleza de su relación. Sin embargo, no da respuestas claras a las preguntas difíciles de su delimitación precisa 0 la resolución de su conflicto potencial o real.

Por encima, este análisis niega que el refuerzo mutuo opera en la democracia y en los derechos humanos como en muchas áreas. Sin embargo, subraya la necesidad de ser franco acerca de lo que está tomando lugar cuando un derecho como el artículo 3 del TEDH triunfa como los deseos de representación de instituciones que están dispuestas a las personas, trayendo unas preguntas a la superficie y considerando una relación entre la democracia y los derechos humanos particularmente como se revela en relación al derecho absoluto como el artículo 3.

El TEDH, no confronta totalmente los problemas de la reseña anterior, como se ha indicado Sahin (2007), que bajo la CEDH «la democracia no significa simplemente que las opiniones de la mayoría siempre deben prevalecer: el equilibrio que se debe conseguir es que garantice el trato justo y adecuado de las personas pertenecientes a las minorías (...)»; esto ha sugerido que sea una búsqueda constante de un equilibrio entre los derechos fundamentales de cada individuo que constituye el fundamento de una «sociedad democrática».

Además, la gran Sala del TEDH ha declarado, en Hirst vs. Reino Unido (2006), en el contexto de los presos con el derecho al voto, que no son numerosas las formas de organizar y ejecutar los sistemas electorales y una gran cantidad de diferencias, entre otras cosas, en el desarrollo histórico, la diversidad cultural y el pensamiento político en Europa que corresponde a cada Estado contratante para moldear en su propia visión democrática.

El discurso de equilibrio en Sahin (2007) y el análisis de la Corte en Hirst (2006), indican un enfoque fluido a la noción de democracia o de una 'sociedad democrática'. Por lo tanto, a pesar de que reconoce que la democracia no equivale estrictamente al gobierno de la mayoría, el TEDH resuelve con frecuencia esta fluidez, haciendo énfasis en su papel de 'supervisión' y en diferir a los Estados contratantes (sin intereses de mente pública democrática, o imperfectamente democrática) ${ }^{11}$. Sin embargo, tal fluidez no está presente en la aplicación del artículo 3, donde ni el margen de apreciación, ni el criterio de proporcionalidad disponible en relación con los derechos calificados son

11 La complejidad y sensibilidad de las cuestiones relacionadas con las políticas de equilibrio de los intereses de la población general [y los intereses de una minoría]... dictan el papel de la Corte en una estricta supervisión. Chapman vs. Reino Unido (2001). 
aplicables. El imperativo de explicar la relación entre el artículo $3 \mathrm{CEDH}$ y la concepción del TEDH de una «sociedad democrática» permanece.

De hecho, el TEDH debe llegar más lejos de la concepción de la democracia que defiende a un grado adecuado a las necesidades de interpretación y aplicación de la Convención en relación con los derechos absolutos, como el artículo 3 del CEDH, sino también en relación con los derechos calificados y derogables. Este esfuerzo servirá para aclarar los contornos de la relación entre la democracia y los derechos consagrados en el CEDH, una aclaración que no sólo es teórica y políticamente significativa, sino también doctrinalmente esencial.

\section{CONCLUSIÓN}

El análisis anterior considera que el artículo 3 del CEDH y la protección que confiere a los individuos contra los deseos de la mayoría o concepciones del interés general en el contexto del debate del derecho a la democracia. El objetivo de la discusión es reiterar o restablecer la convocatoria de (re) considerar los contornos precisos de la relación entre la democracia y los derechos humanos. El análisis plantea cuestiones de primacía y condicionalidad, para determinar en definitiva qué triunfa, lo que es una condición sine qua non podría decirse que resuena más allá del CEDH y que necesita ser enfrentado dentro del mismo CEDH; por lo que se sugiere que es hora de reconocer que precisamente debido a la discordia y la incertidumbre en torno a su interpretación, la democracia debe ser interpretada como un concepto autónomo por el TEDH.

En la medida en que la democracia ya está siendo interpretada de manera autónoma por el TEDH, se necesita una cuenta más transparente de precisión que determine cómo se delimita la democracia a la luz de los derechos protegidos por el CEDH, derechos que se consideran absolutos, como el artículo 3 en mención. Esto es un imperativo importante en un momento en que el debate de la democracia y los derechos humanos son prominentes desde las cafeterías, los salones de clases, los tribunales, los organismos internacionales, y las legislaturas de todo el mundo.

\section{REFRENCIAS BIBLIOGRÁFICAS}

- Steiner, H. (2008). Las dos caras de la misma moneda? La Democracia y los Derechos Humanos Internacionales. Revista Israelí de Derecho. 41-445.

- Franck, T. (1992). El Emergente Derecho a la Gobernabilidad Democrática. Revista Americana de Derecho Internacional 46.

- Ferrajoli, L. (2011). El paradigma normativo de la democracia constitucional. Derecho Constitucional Europeo 5.

- Koen, A. \& Rummens, S. (2007). El populismo contra la democracia. 55 (2) Estudios Políticos.

- Loughlin, M. (2001). Derechos, la democracia y la ley en: (eds.) Campbell, T. y Keith, E. y Tomkins, A. Ensayos escépticos sobre Derechos Humanos. Oxford University Press, Oxford, UK, 41-60.

- David, B. (1999). Democracia y Derechos Humanos. Polity, Cambridge.

- Fredman, S. (2001). El escepticismo bajo Escrutinio: Derecho del Trabajo y Derechos Humanos en T. Campbell, K. Ewing y A. Tomkins, eds. Ensayos escépticos sobre Derechos Humanos. Oxford, Oxford University Press.

- Marks, S. \& Clapham, A (2005). Derechos Humanos Internacional. Oxford University Press.

- $\quad$ Ober, J. \& Hedrick, C. (1996). Demokratia: Una conversación sobre Democracias, antigua y moderna. Princeton University Press.

- Ubong, E. (2007). Democracia y derechos humanos: revaluar la retórica de la «interdependencia y refuerzo mutuo»' Revista de Derecho y Política Internacional del Comercio 91.

- Sadurski, W. (2006). La legitimidad de Derecho y Democracia-Plus. 26 (2). Oxford Revista de Estudios Jurídicos. 377-393.

- Harvey, C. \& Livingstone, S. (2001). La protección de los marginados: el papel de la CEDH» 51 (3) Irlanda del Norte Legal Trimestral 445.

- Pinelli, C. (2011). El desafío populista a la democracia constitucional. (1) Derecho Constitucional Europeo 5.

- Lord Hailsham, Richard Dimbleby Lecture, 14 de octubre 1976.

- Jowell, J. (2006). Soberanía parlamentaria bajo la nueva hipótesis constitucional. Ley Pública 562. 
- Kyritsis, D. (2012).Revisión de la Constitución y la democracia representativa» 32 (2). Revista de Estudios Jurídicos. Oxford Press.

- Harvey, P. (2004). Democracia militante y el Convenio Europeo de Derechos Humanos» 29 (3). Revista de Derecho Europeo. 407.

- Sen, A. (1999). La democracia como un valor universal. Diario de la Democracia. 10 (3).

- Dworkin (1996). La Ley de Libertad: La lectura moral de la Constitución de Estados Unidos. Harvard University Press,

- Letsas. G. (2004). La verdad en conceptos autónomos: cómo interpretar la CEDH. 15 (2) EJIL 279-303.

- $\quad$ Elster, J. (1984). Estudios en la racionalidad y la irracionalidad. Cambridge: Cambridge University Press.

- $\quad$ Larry A. (1998). Constitucionalismo: Fundaciones Filosóficas. Cambridge: Cambridge University Press.

- Habermas, J. (1996). Entre Hechos y Normas. Aportes para una teoría del discurso de Derecho y la Democracia. Cambridge: MIT Press.

- Cohen, J. (1988). Democracia y Libertad, en Jon Elster (ed), democracia deliberativa. Cambridge: Cambridge University Press.

- Lyell, N. (1997). ¿A dónde Estrasburgo? ¿Por qué Gran Bretaña debería pensar largo y tendido antes de la incorporación de la Convención Europea de Derechos Humanos. Revista Europea de Derechos. 132, 136.

- Fiona de Londras, (2013). Funcionalidad dual y la fragilidad persistente del Tribunal Europeo de Derechos Humanos. 1 EHRLR 38, 40

- Dzehtsiarou, K. \& Greene, A. (2013). Reestructuración del Tribunal Europeo de Derechos Humanos: Preservar el derecho de petición individual y Promoción de constitucionalismo.

- Mavronicola, N. (2012). ¿Qué es un derecho absoluto? Rights Law Review 723.

- Gewirth, A. (1981). ¿Hay derechos absolutos? «31 (122) El filosófico Trimestal. 1, 2.

- Bjorge, E. (2011). 'La tortura y las «bombas de relojería» escenarios 127 Ley Trimestral 196.

- Mavronicola, N. (2013) 'Güler y Öngel v Turquía: El artículo 3 de la Convención Europea de De- rechos Humanos y el discurso de Estrasburgo, en la utilización justificada de fuerza 76 (2) Derecho Moderno Revisión.

- Dworkin, R. (1977). Los derechos en serio. Cambridge, MA: Harvard University Press.

- Lynn, N. \& Lea, S. (2003). Una amenaza fantasma y la nueva segregación racial: la construcción social de los solicitantes de asilo en el Reino Unido '14 (4) Discurso y sociedad 425.

- Mavronicola, N. \& Messineo F. (2013). Relativismo absoluto? El debilitamiento del artículo 3 del CEDH en Ahmad v Reino Unido, 76 (3) Revista de Derecho. 589-603.

- Mavronicola, N. (2013) Güler y Öngel v Turquía: El artículo 3 de la Convención Europea de Derechos Humanos y el discurso de Estrasburgo, en el uso justificado de la fuerza '76 (2) Revista Europea de Derecho Moderno 370-382

- Marquand, C. (1994). Protección de los derechos humanos y de las minorías. Ley Pública 359, 365.

- O'Connell, R. (2006). Hacia una concepción fuerte de la democracia en la Convención de Estrasburgo. Revista Europea de Derechos Humanos. pp.281, 283.

- Bogdandy, Von. \& Venzke, I. (2012). En nombre de quién? Una investigación de los tribunales internacionales de la autoridad pública y su justificación democrática. 23 (1) Revista Europea de Derecho Internacional 7.

- Dzehtsiarou, K. \& Greene, A. (2011). La legitimidad y el futuro de la Corte Europea de Derechos Humanos: Perspectivas críticas de la academia y practicantes 12 (10) Ley alemana Diario 1707.

- Harvey, C. (2004). Hablando de los Derechos Humanos. EHRLR 500, 510.

- Mouffe, C. (2000). La Paradoja Democrática. Londres: Verso.

- Bickel, A. (1962). La rama menos peligrosa: la Corte Suprema en el bar de la política (BobbsMerrill, Indianapolis).

- Ekins, R. (2003). Supremacía Judicial y el Estado de Derecho. 119 Ley Trimestral 127;

- Waldron, J. (2006). El núcleo del caso en contra de Revisión Judicial, 115 Yale LJ 1346, 1394

- Lever, A. (2007) ¿Es la revisión judicial antidemocrática?. Ley Pública. 
- Wheatley, S. (2007). Minorías en el marco del CEDH y la construcción de una sociedad democrática. Ley Pública.

- Huntington, S. (1991). La Tercera Ola - Democratización a finales del siglo XX Oklahoma.

- Laws, J. (2012). The Good Constitution. 71 (3) Ley Cambridge Diario 567, 568.

- Dworkin, R. (1996). La Ley de Libertad: La lectura moral de la Constitución de Estados Unidos (Harvard University Press, Cambridge, Massachusetts.

- Dworkin, R. (2000). Soberano Virtud: La Teoría y Práctica de la Igualdad. Harvard University Press. Cambridge: Massachusetts.

- Wouters, k. (2009). Normas jurídicas internacionales para la protección contra la devolución. Intersentia, 187-358.

\section{REFERENCIAS JURISPRUDENCIALES}

- Sahin vs. Turquía (2007) 44 EHRR

- $\quad$ Gäfgen vs. Alemania (2011) 52 EHRR 1.

- $\quad$ Pares vs. Grecia (2001) 33 EHRR 1192.

- $\quad$ MSS vs. Bélgica y Grecia (2011) 53 EHRR 2.

- Jashi vs. Georgia (App No 10799/06), Sentencia de 8 de enero de 2013.

- Irlanda vs. Reino Unido (1979-1980) 2 EHRR 25.

- Chahal vs. Reino Unido (1997) 23 EHRR 413, párrafo 79. Véase también Saadi vs. Italia (2009) 49 EHRR 30, párrafo 127.

- $\quad$ Gäfgen vs. Alemania (2011) 52 EHRR 1.

- Keenan vs. Reino Unido (2001) 33913 EHRR.

- Riviere vs. Francia (App No 33834/03), Sentencia de 11 de julio de 2006.

- aahin vs. Turquía (2007) 44 EHRR

- Hirst vs. Reino Unido ( $\left.{ }^{\circ}{ }^{2} 2\right)$ (2006) 42 EHRR 41.

\section{PÁGINAS WEB}

- Red de ONG de Puntos Focales de Integración, sesión informativa sobre la Política de la participación cívica y política de los refugiados y los inmigrantes en Europa, disponible en http: / / www.ecre.org/component/content/article/57policy-papers/180-integration-policy-briefings. html [último acceso 19 de mayo 2013].
- James Slack, 'Deja de injerencia en los casos de asilo, no elegidos jueces Euro advertidos por 47 países», The Mail Online, 28 abril 2011, disponible enhttp://www.dailymail.co.uk/news/ article-1381351/Stop-meddling-asylum-casesunelected-Euro-judges-warned-47-countries.html [último acceso 19 de mayo 2013].

- Declaración Universal de los Derechos Humanos, 10 de diciembre de 1948, 217 A (III), disponible en: http://www.unhcr.org/refworld/docid/3ae 6b3712c.html [último acceso 19 de mayo 2013]. Ver más Tom Christiano, 'Democracia', The Stanford Encyclopedia of Philosophy (Fall 2008 Edition), Edward N. Zalta (ed.), Disponible en http:/ /plato.stanford.edu/archives/fall2008/entries/ democracy/ [último acceso 19 de mayo 2013].

- Boffrey, D. (2013). La inmigración es el mayor problema de la sociedad británica, muestra encuesta de público», The Observer, 13 de enero de 2013, disponible en http://www.guardian.co. uk/uk/2013/jan/13/immigration- british-sociedadmayor-problema [último acceso 19 de mayo].

- White, I. (Parlamento y Constitución Centro), Estándar Nota sobre Prisioneros de Derecho al Voto (Cámara de los Comunes Biblioteca, 2013), disponible en http://www.parliament.uk/briefingpapers/SN01764 [último acceso 19 de mayo 2013].

- General de la ONU, Declaración y Programa de Acción de Viena de 12 de julio de 1993, A / CONF.157 / 23, disponible en http://www.unhcr. org/refworld/docid/3ae6b39ec.html [Ultimo acceder 19 de mayo 2013].

- Abraham Lincoln, Discurso de Gettysburg, 19 de noviembre 1863.

- Pinelli, n 15 supra, 6: 'Resultados de la democracia constitucional de ajustes continuos de estos principios e instituciones potencialmente conflictivos, que están abiertas a diversas interpretaciones y, por lo tanto, el conflicto.

- Messineo, F. obligaciones de no devolución en Derecho Internacional Público: Hacia un Estado Nuevo Protección?, En S. Juss (ed.), Compañero de Investigación de Teoría y Política Migratoria (Ashgate, 2012), disponible en http: / /papers.ssrn.com/sol3/papers.cfm? ABSTRACT_id=1802800 [último acceso 19 de mayo 2013] 